\title{
The association between circulating IGF1, IGFBP3, and calcium: results from NHANES III
}

\section{Mieke Van Hemelrijck, Thurkaa Shanmugalingam, Cecilia Bosco, Wahyu Wulaningsih and Sabine Rohrmann ${ }^{1}$}

Cancer Epidemiology Group, Division of Cancer Studies, King's College London, London, UK ${ }^{1}$ Division of Chronic Disease Epidemiology, Epidemiology, Biostatistics and Prevention Institute (EBPI), University of Zurich, Hirschengraben 84, 8001 Zurich, Switzerland
Correspondence should be addressed to S Rohrmann Email

sabine.rohrmann@ ifspm.uzh.ch

\begin{abstract}
Background: Despite mounting evidence linking both calcium and IGF1, there is a lack of studies investigating any association between circulating levels of IGF1 and serum calcium. Methods: Serum calcium, IGF1, and IGF-binding protein 3 (IGFBP3) were measured for 5368 participants in NHANES III. We calculated multivariable-adjusted geometric means of serum concentrations of IGF1, IGFBP3, and IGF1/IGFBP3 by categories of calcium (lowest $5 \%$ $(<1.16 \mathrm{mmol} / \mathrm{l})$, mid $90 \%$, and top $5 \%(\geq 1.31 \mathrm{mmol} / \mathrm{l}))$. We also performed stratified analyses by sex, age, ethnicity, BMI, serum levels of vitamin $D$, and bone mineral density (BMD).

Results: Overall, we found that circulating calcium was positively associated with circulating levels of IGF1 and IGFBP3, but not their molar ratio (i.e., geometric mean of IGF1 by increasing calcium categories: $237.63,246.51$, and $264.22 \mathrm{ng} / \mathrm{nl} ; P_{\text {trend }}: 0.43$; $\left.P_{\text {first vs third category }}: 0.01\right)$. In particular, these associations were observed in women, people aged $<60$, non-Hispanic whites, those with vitamin $D$ levels above the mean, and those with low BMD. In contrast, there was an inverse association with the molar ratio for those with BMI $\geq 30 \mathrm{~kg} / \mathrm{m}^{2}$

Conclusion: We found an overall positive association between circulating levels of IGF1 and IGFBP3 and serum calcium. However, stratification by potential effect-modifiers did not support all suggested hypotheses. Our findings provide more insight into the interplay between calcium and IGF1, which in the future can be investigated in larger observational studies allowing for additional stratifications based on a combination of the different effect-modifiers investigated here.
\end{abstract} Key Words
- IGF-1
- IGFBP3
- calcium
- cross-sectional

\section{Introduction}

Both insulin-like growth factor 1 (IGF1) and calcium metabolisms have been linked to chronic diseases such as cardiovascular disease and cancer $(1,2,3,4)$. IGF1 is a polypeptide hormone implicated in cell differentiation, proliferation, and apoptosis. IGF1 is mainly carried in the blood within a ternary complex with IGF-binding protein 3 (IGFBP3). This complex stabilises IGF1 such that its clearance is reduced and its supply to target cells is prolonged $(5,6)$. Different biological mechanisms have been suggested for the interaction between IGF1 and

$$
\begin{array}{lr}
\text { http://www.endocrineconnections.org } & \text { ( } 2015 \text { The authors } \\
\text { DOI: } 10.1530 / E C-15-0039 & \text { Published by Bioscientifica Ltd }
\end{array}
$$


calcium metabolism. It has been shown in several experimental studies $(7,8,9)$, that IGF1 increases the activity of $1 \alpha$ hydroxylase which transforms the inert 25-hydroxyvitamin D into its active form 1,25-dyhydroxyvitamin $\mathrm{D}$. Active vitamin $\mathrm{D}$ is a well known regulator of serum calcium (10). Furthermore, a recent systematic review, based on 14 studies reporting clinical effects of IGF1 administration, showed that IGF1 increases bone resorption and bone formation (11), thus also suggesting a potential interaction between calcium and IGF1 in terms of bone metabolism (11).

Circulating levels of IGF1 have been associated with milk and calcium intake $(6,12,13)$. For instance, a study based on 4731 men and women in the European Prospective Investigation into Cancer and Nutrition (EPIC) assessed the association between dietary intake and serum concentrations of IGF1, IGFBP1, IGFBP2, and IGFBP3 (6). They found that for each s.D. increase in total and dairy protein and calcium intake, there was an increase in IGF1 concentration of $2.5,2.4$, and $3.3 \%$ respectively ( $P$ for trend: $<0.001$ for all) and a decrease in IGFBP2 of $3.5,3.5$, and $5.4 \%$ respectively ( $P$ for trend: $<0.001$ for all). Only calcium intake was associated with IGFBP3 (0.8\%; $P<0.05)$, and no associations were found for IGFBP1 (6). Despite several studies investigating a link between dietary intake of calcium and IGF1, to our knowledge no study has yet investigated whether there is an association between circulating levels of IGF1 and serum calcium. Although serum calcium concentrations are tightly regulated, a positive association between calcium intake and levels of ionized calcium has been shown (14). Hence, we evaluated this relationship using cross-sectional data from the Third National Health and Nutrition Examination Survey (NHANES III), a nationally representative sample of non-institutionalized US Americans.

\section{Methods}

\section{Study population}

The National Center for Health Statistics (NCHS) conducted NHANES III between 1988 and 1994 (15), and designed it as a multistage stratified, clustered probability sample of the USA civilian non-institutionalized population who was at least 2 months old. All subjects participated in an interview conducted at home and an extensive physical examination, which included a blood sample performed at a mobile examination center (15). Study participants were randomly assigned to participate in either the morning or afternoon/evening examination session. We selected all men and women aged $20+$ years who had serum measurements for IGF1, IGFBP3, and calcium $(n=5368)$ taken during a morning examination.

\section{Exposure measurements}

Information on age, race/ethnicity, cigarette smoking, alcohol consumption, and physical activity was collected during the interview. Race and ethnicity were combined into four racial/ethnic groups: non-Hispanic white, non-Hispanic black, Mexican American, and other. Participants were classified as never, former, and current smokers based on the self-reported smoking habits. Frequency of alcohol consumption was measured by a food frequency questionnaire and categorized by times per week. Vigorous physical activity was defined by the following activities: jogging or running; swimming or aerobics (for individuals 40 years or older); biking, dancing, gardening, and calisthenics (for individuals 65 years or older); and walking and lifting weights (for individuals 80 years and older). Participants were defined as being diabetic when they reported a diagnosis of diabetes or when they were using insulin or diabetic medication. Height, weight, and waist circumference were measured during the examination procedure. BMI was calculated by dividing weight in kilograms by height in meters squared (16). Serum calcium was measured using a Hitachi 737 Analyzer (Boehringer Mannheim Diagnostics, Indianapolis, IN, USA) $(17,18)$. 25-Hydroxy vitamin D was measured using the Diasorin RIA Kit (Diasorin, Stillwater, MN, USA) on frozen serum from 1994 to 1995. Coefficients of variations $(\mathrm{CV})$ from quality control samples ranged from 13 to $19 \%$. The RIA kit was calibrated using HPLC purified vitamin D every 6 months. Bone mineral density (BMD) of femur neck was measured using dual-energy X-ray absorptiometry in 4799 participants. Low BMD was defined as any BMD $<1$ s.D. below the mean of BMD in young adults (20-29 years) (19). The Institutional Review Board of the NCHS, Centers for Disease Control and Prevention approved the protocols for the conduct of NHANES III. Written informed consent was obtained from all participants.

\section{IGF1 and IGFBP3 measurements}

IGF1 and IGFBP3 were measured by Diagnostic Systems Laboratories (Webster, TX, USA). IGF1 concentrations were quantified by ELISA (DSL 10-5600), which is an enzymatically amplified 'one-step' sandwich-type immunoassay.

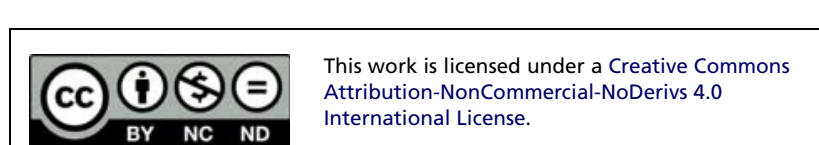


This procedure includes an extraction step during which IGF1 is separated from its binding protein in serum. IGFBP3 concentrations were measured with an IRMA (DSL 6600). This is a non-competitive assay in which the analyte to be measured is 'sandwiched' between two antibodies. The first anti-body is placed to the inside wall of the tube and the other is radiolabeled for detection. A single technician performed all procedures. Throughout the study, samples were reanalysed if the CV for replicate samples from a single vial was $>15 \%$. CV varied significantly among individual QC subjects ranging from 12.3 to $17.6 \%$ for IGF1 and 8.9 to12.8\% for IGFBP3 $(20,21)$. Their molar ratio is defined by dividing IGF1 by IGFBP3.

\section{Statistical analysis}

All analyses were conducted with Statistical Analysis Systems (SAS) release 9.4 (SAS Institute, Cary, NC, USA) and SUDAAN 9.0 Software (Research Triangle Park, NC, USA) as implemented in SAS 9.2. Morning sampling weights for NHANES III were used to account for sampling variability and to adjust for differential probability of selection of persons (15). First, we calculated the age-adjusted means or percentages of characteristics of the men by categories of serum calcium concentration by adjusting for the age distribution of the USA population according to the 2000 census. Since the calcium metabolism is tightly controlled, the following categories of calcium were chosen to capture extreme variation: the bottom 5\%, mid 90\%, and top 5\%. Next, we calculated crude and adjusted geometric mean concentrations of IGF1, IGFBP3, their molar ratio and their 95\% CIs by categories of serum calcium using linear regression. The multivariable model was adjusted for age (continuous), sex, race/ethnicity and factors that have been associated with IGF1 in previous studies: waist circumference, BMI, vigorous physical activity (yes or no), serum levels of vitamin $\mathrm{D}$, cigarette smoking (never, former, and current), alcohol intake $(<2,2-3,4-6$ times a week, or daily or more), and history of diabetes (yes or no) $(5,6,22)$. We also adjusted for serum levels of albumin to obtain an estimate of the free ionized calcium levels (serum normalized calcium), which is the amount of metabolically active serum calcium (23). In addition, we performed stratified analyses for sex, age groups (20-39, 40-59, and $\geq 60$ years), racial/ethnic groups, obesity $(<25,25-30$, and $\geq 30 \mathrm{~kg} / \mathrm{m}^{2}$ ), serum levels of vitamin D (the mean of $<25.7$ or $\geq 25.7 \mathrm{ng} / \mathrm{ml}$ ) and BMD (normal and low) to determine whether the results were consistent between men and women, between younger and older people, between different racial/ethnic groups, and between people with different vitamin D levels. We performed a test for interaction for all the preceding stratified analyses by introducing an interaction term in the linear regression models and testing its coefficient with the Wald test. These stratifications were chosen based on previous findings for associations with calcium and $\operatorname{IGF} 1(5,6,22)$.

\section{Results}

Baseline characteristics of the study population by categories of serum calcium are shown in Table 1 . Mean age was slightly higher for those in the extreme categories, which also contained more women. No clear pattern by ethnicity was observed, nor was there a difference in waist circumference by calcium categories. Vitamin D levels were highest for those in the middle category, whereas the proportion of those with a history of diabetes and those who were vigorously physically active was highest for those in the extreme categories.

When comparing the age, sex, and ethnicity adjusted geometric means of the IGF biomarkers by categories of serum normalized calcium, a statistically significant positive association was observed for IGF1 and IGFBP3 (Table 2). These trends remained in the fully adjusted model, but statistical significance disappeared for the overall trend. It did, however, remain when comparing the lowest and top 5\% of the calcium categories. Neither model showed an association between the molar ratio of IGF1 and IGFBP3 and serum calcium levels.

When stratifying by sex, effect modification was observed for the molar ratio $\left(P_{\text {interaction }}=0.03\right.$; Table 3$)$. However, for women there was a positive association between each IGF biomarker measured and categories of serum normalized calcium, whereas for men only a weak positive pattern was seen for IGFBP3.

No effect modification by age categories was observed (Table 3). However, the positive association between each IGF biomarker measured and categories of serum normalized calcium were slightly less pronounced for those age $60+$.

Based on the $P_{\text {interaction, }}$ effect modification by ethnicity was only present for IGFBP3. There was a positive trend with serum calcium across ethnicity groups, but the means were in general higher for non-Hispanic whites than for non-Hispanic blacks or Mexican Americans (Table 3).

An effect of BMI for the association between markers of IGF1 and serum calcium was observed for IGF1 and the molar ratio. In contrast to all the positive associations observed previously, there was an inverse association between the molar ratio and calcium for those with BMI $\geq 30 \mathrm{~kg} / \mathrm{m}^{2}$ (Table 3 ). 
Table 1 Age-adjusted (standardized to the 2000 USA census age distribution) weighted characteristics by levels of serum normalised calcium, NHANES III 1988-1991.

\begin{tabular}{|c|c|c|c|}
\hline & \multicolumn{3}{|c|}{ Serum normalized total calcium $(\mathrm{mmol} / \mathrm{l})$} \\
\hline & Lowest $5 \%,<1.16$ & Mid $90 \%, 1.16-1.31$ & Top $5 \%, \geq 1.31$ \\
\hline$n$ & 182 & 4852 & 324 \\
\hline \multicolumn{4}{|l|}{ Age (years) } \\
\hline Mean (S.E.M.) & $47.52(0.63)$ & $45.91(0.14)$ & $46.13(0.56)$ \\
\hline \multicolumn{4}{|l|}{$\operatorname{Sex}(\%)$} \\
\hline Men & 38.65 & 47.33 & 39.88 \\
\hline Women & 61.25 & 52.67 & 60.12 \\
\hline \multicolumn{4}{|l|}{ Race - ethnicity (\%) } \\
\hline Non-Hispanic white & 84.66 & 76.98 & 74.30 \\
\hline Non-Hispanic black & 8.18 & 10.26 & 13.75 \\
\hline Mexican American & 5.21 & 4.99 & 3.41 \\
\hline Other & 1.94 & 7.76 & 8.54 \\
\hline \multicolumn{4}{|l|}{ Waist circumference $(\mathrm{cm})$} \\
\hline Mean (S.E.M.) & $92.75(1.50)$ & $92.49(0.38)$ & $91.21(1.06)$ \\
\hline \multicolumn{4}{|l|}{ BMI $\left(\mathrm{kg} / \mathrm{m}^{2}\right)$} \\
\hline Mean (s.E.M.) & $26.7(0.66)$ & $26.77(0.17)$ & $26.32(0.41)$ \\
\hline \multicolumn{4}{|l|}{ Cigarette smoking (\%) } \\
\hline Never & 41.52 & 46.91 & 40.55 \\
\hline Former & 30.21 & 25.88 & 34.05 \\
\hline Current & 28.26 & 27.21 & 25.40 \\
\hline \multicolumn{4}{|l|}{ Alcohol intake (\%) } \\
\hline Up to once a week & 67.48 & 63.96 & 66.89 \\
\hline Two to three times a week & 9.72 & 15.13 & 11.90 \\
\hline Four to six times a week & 11.36 & 11.21 & 9.85 \\
\hline Daily or more & 6.61 & 9.70 & 11.36 \\
\hline Vigorous physical activity (\%) & 11.92 & 9.89 & 11.49 \\
\hline Diabetes $(\%)$ & 6.24 & 3.78 & 5.88 \\
\hline \multicolumn{4}{|l|}{ Calcium (mmol/l) } \\
\hline Mean (s.E.M.) & $1.13(0.003)$ & $1.23(0.002)$ & $1.33(0.003)$ \\
\hline \multicolumn{4}{|l|}{ Vitamin D (ng/ml) } \\
\hline Mean (s.E.M.) & $27.59(1.06)$ & $29.64(0.36)$ & $29.02(1.18)$ \\
\hline \multicolumn{4}{|c|}{$\begin{array}{l}\text { Femoral neck bone mineral density } \\
\left(\mathrm{gm} / \mathrm{cm}^{2}\right)\end{array}$} \\
\hline Mean (s.E.M.) & $0.83(0.01)$ & $0.82(0.003)$ & $0.80(0.01)$ \\
\hline \multicolumn{4}{|l|}{ Albumin (g/l) } \\
\hline Mean (S.E.M.) & $39.92(0.48)$ & $41.12(0.21)$ & $42.16(0.25)$ \\
\hline
\end{tabular}

No statistically significant effect modification was observed by median 25-hydroxy vitamin D concentration. However, the positive association between markers of IGF1 and serum calcium was more pronounced for those with vitamin D levels above the mean (Table 3 ).

Finally, a lack of effect modification was also seen when stratifying by BMD. Nevertheless, a statistically significant positive association between IGF1 markers and serum calcium was only observed in men with normal BMD (Table 3).

\section{Discussion}

This cross-sectional study investigated how serum levels of calcium are correlated with circulating markers of the IGF1 metabolism. Overall, we found that circulating calcium

\begin{tabular}{lr}
\hline http://www.endocrineconnections.org & ( 2015 The authors \\
DOI: 10.1530/EC-15-0039 & Published by Bioscientifica Ltd
\end{tabular}

was positively associated with circulating levels of IGF1 and IGFBP3, but not their molar ratio. These associations were, in particular, observed in women, people aged $<60$, non-Hispanic whites, those with vitamin D levels above the median, and normal BMD. In contrast, there was an inverse association with the molar ratio for those with BMI $\geq 30 \mathrm{~kg} / \mathrm{m}^{2}$.

An indirect biological association between calcium and IGF1 has been suggested by the documented links between IGF1 and components of bone metabolism. For instance, vitamin $\mathrm{D}$ is suggested to increase circulating IGF1 and IGFBP3, whereas IGF1 has been reported to stimulate renal production of vitamin $\mathrm{D}$, which further modifies calcium availability and suppresses parathyroid hormone (PTH) secretion (5). IGF1 is produced in large amounts by osteocytes, and absence of osteocytes-derived

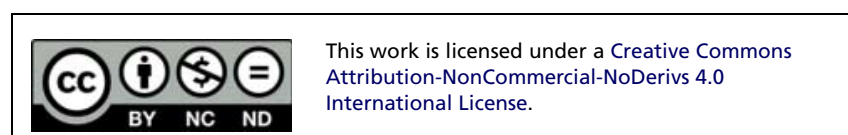


Table 2 Geometric mean ( $95 \% \mathrm{Cl}$ ) of IGF1 concentrations by extreme measures of calcium in a nationally representative sample in NHANES III. All adjusted means take into account age, race/ethnicity, BMI, waist circumference, diabetes, cigarette smoking, alcohol intake, vigorous physical activity, and serum levels of vitamin D and albumin.

\begin{tabular}{|c|c|c|c|c|c|}
\hline & \multicolumn{3}{|c|}{ Geometric mean $(95 \% \mathrm{Cl})$} & \multirow{2}{*}{$\begin{array}{l}P \text { for } \\
\text { trend }\end{array}$} & \multirow{2}{*}{$\begin{array}{c}P \text { for } t \text {-test } \\
\text { between lowest } \\
\text { and top } 5 \%\end{array}$} \\
\hline & Lowest $5 \%,<1.16$ & Mid $90 \%, 1.16-1.30$ & Top $5 \%, \geq 1.30$ & & \\
\hline \multicolumn{6}{|c|}{ Age, sex, and race adjusted model } \\
\hline IGF1 (ng/nl) & $233.83(221.87-246.44)$ & 246.19 (239.43-253.14) & 265.55 (250.53-281.47) & 0.003 & 0.002 \\
\hline IGFBP3 $(\mu \mathrm{g} / \mathrm{g})$ & $4123.67(3897.35-4363.14)$ & $4345.08(4286.72-4404.24)$ & 4517.89 (4399.05-4639.94) & 0.002 & 0.005 \\
\hline IGF1/IGFBP3 & $0.205(0.19-0.22)$ & $0.205(0.20-0.21)$ & $0.212(0.20-0.22)$ & 0.220 & 0.35 \\
\hline \multicolumn{6}{|c|}{ Fully adjusted model } \\
\hline IGF1 (ng/nl) & $237.63(224.28-251.77)$ & $246.51(239.51-253.37)$ & $264.22(249.28-280.06)$ & 0.430 & 0.01 \\
\hline IGFBP3 $(\mu \mathrm{g} / \mathrm{g})$ & $4157.63(3947.97-4678.42)$ & $4351.17(4294.40-4408.69)$ & $4521.05(4404.72-4640.46)$ & 0.660 & 0.006 \\
\hline IGF1/IGFBP3 & $0.206(0.19-0.22)$ & $0.205(0.20-0.21)$ & $0.211(0.20-0.22)$ & 0.70 & 0.56 \\
\hline
\end{tabular}

IGF1 has been shown to impair bone development and turnover $(24,25)$. IGF1 is observed to bind directly to calcium channels, which opens calcium stores $(26,27)$. All this evidence indicates a complex interplay between IGF1 and calcium homeostasis as well as its regulators. However, no study to date has investigated the association between circulating levels of markers of IGF1 metabolism and calcium in the population.

Epidemiological evidence for a potential link follows from studies investigating dietary intake of calcium and dairy products. With respect to the markers of IGF1 studied here, EPIC found a positive association between total and dairy protein and calcium intake and IGF1 as well as between calcium intake and IGFBP3 (6). Another study, based on 1798 men, also showed positive associations between diary product, dairy protein, and calcium intake and IGF1. However, they did not find any associations with IGFBP3 (28), which is in contrast with our findings. Overall our findings corroborate a positive association between IGF1 and serum calcium, and potentially also IGFBP3.

In a case-control study nested in the Physicians' Health Study, plasma samples of IGF1 for 14915 men was assessed in relation to intake of low-fat milk or calcium from dairy food (29). Despite their primary focus on colorectal cancer, Ma et al. found that low-fat milk was positively associated with plasma with plasma levels of IGF1, IGFBP3, and their molar ratio, indicating a relationship between intake of dairy products and a modest increase in circulating IGF1 levels. Our study assessed similar associations as in the study by Ma et al., but now investigating serum calcium levels, and only observed a positive association with the molar ratio for women, not for men. The lack of an association for men could reflect the difference in patterns of calcium supplement use for men and women. Women are thought to take these supplements more frequently than men (30).

In fact, all markers studied were positively associated with serum levels of calcium among women. This is consistent with what was found for calcium intake. A casecontrol study nested within EPIC evaluated the relationship of diet with IGF1 and IGFBP3 in women. IGF1 was positively associated with intake of milk and calcium, however, no associations were found for IGFBP3 in this study (31). Similar findings came from a British study showing a $25 \%$ increase in calcium intake to be associated with an increase in IGF1 of $5.92 \mathrm{ng} / \mathrm{ml}$ (28), which the authors suggested follows from the high correlation between calcium and milk in dietary surveys. A study by Holmes et al. (13) observed an association between dietary calcium and IGF1, but not for total calcium intake including supplementation.

Stratification by age mainly showed positive associations for those $<60$ years old, which could potentially be driven by menopausal status of women as sex-stratification showed stronger associations for women. However, our sample size was too small to perform a combined age and sex stratification. It has previously been shown that both IGF1 and calcium decrease with age in women (32), which could potentially explain why there is a stronger association between these markers in younger participants.

Effect-modification by ethnicity is of interest, especially due to the implication of race/ethnicity on one's susceptibility to chronic diseases such as cancer. For instance, black men have a higher risk of getting prostate cancer (33), and higher levels of IGF1 and lower levels of IGFBP3 have been associated with an increased risk of prostate cancer (34). A cross-sectional analysis based on 95 African American and 138 white males aged 33-83 years
This work is licensed under a Creative Commons Attribution-NonCommercial-NoDerivs 4.0 International License. 
Table 3 Stratified geometric mean $(95 \% \mathrm{Cl})$ of IGF1 concentrations by extreme measures of calcium in a nationally representative sample in NHANES III. All models are adjusted for age, race/ethnicity, waist circumference, diabetes, BMI, cigarette smoking, alcohol intake, vigorous physical activity, and serum levels of vitamin D and albumin.

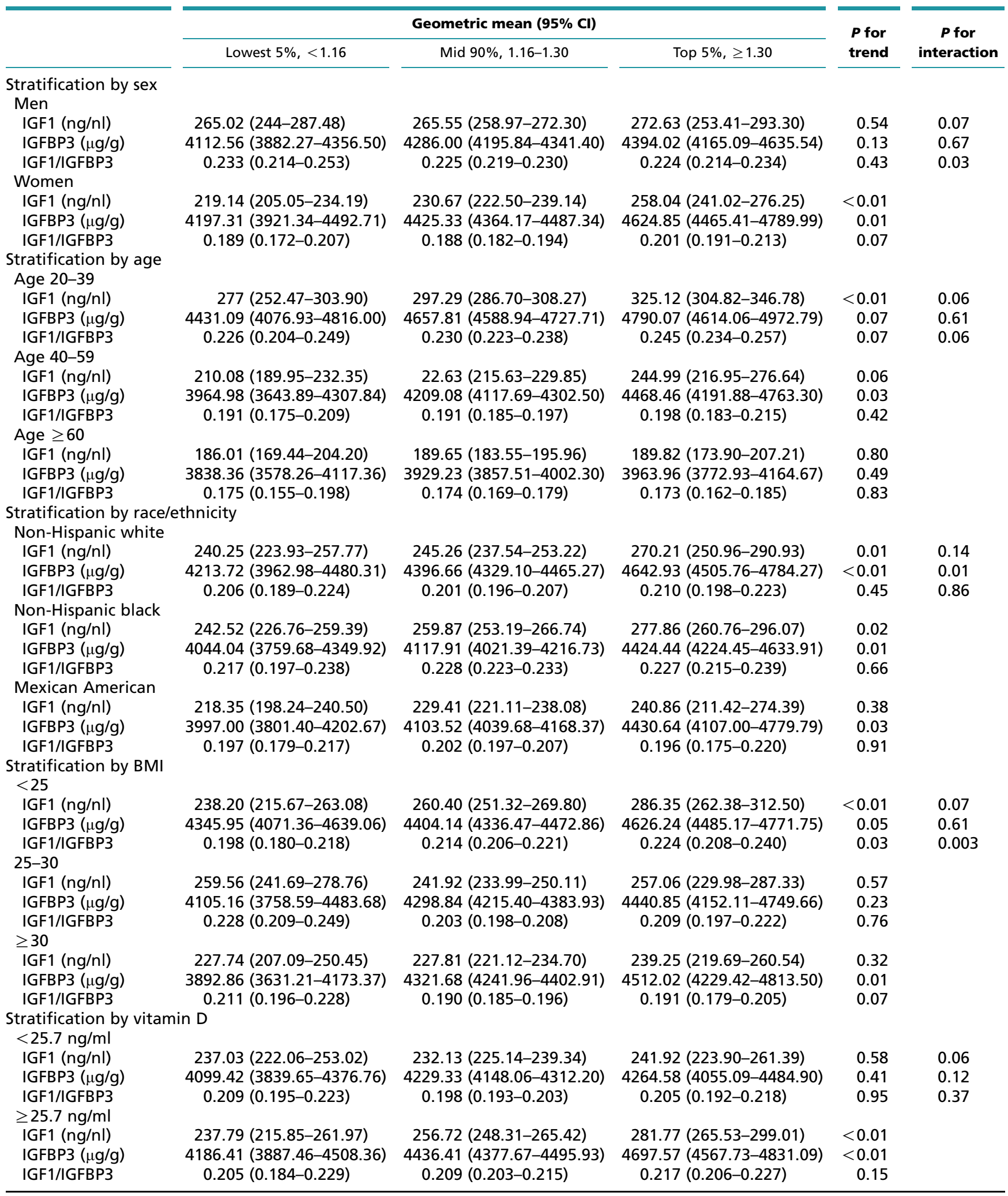

http://www.endocrineconnections.org DOI: 10.1530/EC-15-0039 (c) 2015 The authors Published by Bioscientifica Ltd
This work is licensed under a Creative Commons Attribution-NonCommercial-NoDerivs 4.0 International License. 


\begin{tabular}{|c|c|c|c|c|c|}
\hline & \multicolumn{3}{|c|}{ Geometric mean $(95 \% \mathrm{Cl})$} & \multirow{2}{*}{$\begin{array}{l}P \text { for } \\
\text { trend }\end{array}$} & \multirow{2}{*}{$\begin{array}{c}P \text { for } \\
\text { interaction }\end{array}$} \\
\hline & Lowest $5 \%,<1.16$ & Mid $90 \%, 1.16-1.30$ & Top $5 \%, \geq 1.30$ & & \\
\hline \multicolumn{6}{|c|}{ Stratification by BMD } \\
\hline \multicolumn{6}{|c|}{ Normal } \\
\hline IGF1 (ng/nl) & $246.90(229.90-265.16)$ & $254.07(246.56-261.80)$ & $274.68(260.26-289.89)$ & 0.006 & 0.33 \\
\hline IGFBP3 $(\mu \mathrm{g} / \mathrm{g})$ & $4155.13(3900.23-4426.69)$ & $4369.92(4307.00-4433.76)$ & $4533.28(4424.43-4644.80)$ & 0.003 & 0.57 \\
\hline IGF1/IGFBP3 & $0.215(0.20-0.23)$ & $0.210(0.20-0.22)$ & $0.219(0.21-0.23)$ & 0.30 & 0.37 \\
\hline \multicolumn{6}{|l|}{ Low } \\
\hline IGF1 (ng/nl) & $199.28(181.53-218.76)$ & 192.08 (183.29-201.29) & 201.60 (174.35-233.12) & 0.68 & \\
\hline IGFBP3 $(\mu \mathrm{g} / \mathrm{g})$ & $4127.39(3766.37-4523.01)$ & 4064.31 (3972.17-4158.59) & $4249.68(3916.16-4611.61)$ & 0.45 & \\
\hline IGF1/IGFBP3 & $0.174(0.16-0.20)$ & $0.171(0.16-0.18)$ & $0.171(0.16-0.19)$ & 0.91 & \\
\hline
\end{tabular}

attending a prostate cancer screening clinic showed that only in African Americans, increasing intake of calcium and dairy servings was positively associated with IGF1 levels (34). Our results showed positive associations between IGF1 and IGFBP3 with calcium levels in Non-Hispanic whites and blacks, but the geometric means of IGF1 were higher for blacks, while the geometric means for IGFBP3 were higher for whites. Thus, our findings for blacks corroborate with the findings by McGreevy et al. (34), however, they did not investigate the association between calcium and IGFBP3 by ethnicity. Moreover, it is difficult to really make a statement about this as we did not observe an effect in men and our sample size was too small to make further effect modification by both ethnicity and sex.

Positive associations between markers of IGF1 metabolism and calcium were mostly apparent in those with BMI $<25 \mathrm{~kg} / \mathrm{m}^{2}$, which is interesting given the mixed findings of both higher and lower free IGF1 concentrations in obese individuals (35). A recent randomised controlled trial allocated 439 overweight or obese postmenopausal women into exercise, dietary weight loss, exercise and dietary weight loss, or control. Even though there were no significant changes in either IGF1 or IGFBP3 in any of the intervention arms compared with the control, the IGF1/IGFBP3 ratio increased significantly in the diet and diet/exercise group compared with control (36), which may be a reflection of changes in BMI. No clear pattern for the ratio was found here in terms of BMI, however it was positively associated with calcium in all apart from those who were overweight.

Only amongst those with high vitamin D levels, we observed a positive association between markers of the IGF1 metabolism and calcium. All geometric means were also higher among those with high vitamin D levels. A recent review confirmed that the interplay between vitamin D and IGF1 is complex as it occurs at both endocrine and paracrine/autocrine levels (5). Our findings corroborate previous biological evidence that vitamin D increases circulating IGF1 and IGFBP3. This positive association also support the notion that IGF1 stimulates renal production of vitamin $\mathrm{D}$, which increases calcium availability (5).

Low IGF1 levels have been linked to bone loss and risk of fracture $(37,38)$. We found a positive association between IGF1 and IGFBP3 with calcium in those with normal BMD of the femur neck. Additionally, levels of IGF1 markers were markedly lower in participants with low BMD, which corroborate prior findings $(32,39,40)$. Although no statistically significant interaction was seen, the stronger link between IGF1 markers and calcium in normal BMD may warrant mechanistic investigations in the IGF1 and calcium axis in presence of bone loss.

This study has several strengths including its generalizability following the use of nationally representative data. Therefore it was also possible in our analysis to perform a stratified analysis by several demographic components. We were able to adjust for many potential confounding factors. A limitation of this study is that we did not have data on free ionized calcium in the NHANES III, and remaining discrepancies may occur even though we have corrected serum calcium based on albumin levels. Additionally, information on other metabolites or regulators of serum calcium such as PTH which may further characterize calcium status is not available in the study. Finally, it is worth noting that our results did not always corroborate what has been found for the associations between calcium intake and circulating levels of IGF1 markers. Even though a positive association has been shown between calcium intake and ionized calcium (14), it is possible that dietary changes are not reflected as strongly by the tightly regulated calcium metabolism measured in blood so that the association with IGF1 markers differs from those for dietary calcium intake. http://www.endocrineconnections.org DOI: 10.1530/EC-15-0039
(C) 2015 The authors Published by Bioscientifica Ltd
This work is licensed under a Creative Commons Attribution-NonCommercial-NoDerivs 4.0 International License. 


\section{Conclusion}

This study showed an overall positive association between circulating levels of IGF1 and IGFBP3 and serum calcium. However, stratification by potential effect modifiers did not support all suggested hypotheses. Nevertheless, our findings did show a stronger association between IGF1 and calcium for those who also had higher vitamin D levels and those with normal BMD. These cross-sectional findings provide more insight into the interplay between calcium and IGF1, which may be important in the context of diseases. This can be investigated in larger observational studies allowing for additional stratifications based on a combination of the different effect modifiers investigated here.

\section{Declaration of interest}

The authors declare that there is no conflict of interest that could be perceived as prejudicing the impartiality of the research reported.

\section{Funding}

This work was supported by Cancer Research UK, as they supported the start-up of the Cancer Epidemiology Group at King's College London.

\section{References}

1 Furstenberger G \& Senn HJ. Insulin-like growth factors and cancer. Lancet Oncology 20023 298-302. (doi:10.1016/S1470-2045(02)00731-3)

2 Colao A. The GH-IGF-I axis and the cardiovascular system: clinical implications. Clinical Endocrinology 200869 347-358. (doi:10.1111/ j.1365-2265.2008.03292.x)

3 Heine GH, Nangaku M \& Fliser D. Calcium and phosphate impact cardiovascular risk. European Heart Journal 201334 1112-1121. (doi:10.1093/eurheartj/ehs353)

4 Fortmann SP, Burda BU, Senger CA, Lin JS \& Whitlock EP. Vitamin and mineral supplements in the primary prevention of cardiovascular disease and cancer: an updated systematic evidence review for the U.S. Preventive Services Task Force. Annals of Internal Medicine 2013159 824-834. (doi:10.7326/0003-4819-159-12-201312170-00729)

5 Ameri P, Giusti A, Boschetti M, Murialdo G, Minuto F \& Ferone D. Interactions between vitamin D and IGF-I: from physiology to clinical practice. Clinical Endocrinology 201379 457-463. (doi:10.1111/ cen.12268)

6 Crowe FL, Key TJ, Allen NE, Appleby PN, Roddam A, Overvad K et al. The association between diet and serum concentrations of IGF-I, IGFBP-1, IGFBP-2, and IGFBP-3 in the European Prospective Investigation into Cancer and Nutrition. Cancer Epidemiology, Biomarkers \& Prevention 200918 1333-1340. (doi:10.1158/1055-9965.EPI-08-0781)

7 Bianda T, Hussain M, Glatz Y, Bouillon R, Froesch E \& Schmid C. Effects of short-term insulin-like growth factor-I or growth hormone treatment on bone turnover, renal phosphate reabsorption and 1,25 dihydroxyvitamin D3 production in healthy man. Journal of Internal Medicine 1997 241 143-150. (doi:10.1046/j.1365-2796.1997.94101000.x)

8 Menaa C, Friedlander G, Corvol M \& Garabédian M. Insulin-like growth factor I, a unique calcium-dependent stimulator of 1,25-dihydroxyvitamin D3 production studies in cultured mouse kidney cells. Journal of Biological Chemistry 1995270 25461-25467. (doi:10.1074/ jbc.270.43.25461)
9 Nesbitt T \& Drezner MK. Insulin-like growth factor-I regulation of renal 25-hydroxyvitamin D-1-hydroxylase activity. Endocrinology 1993132 133-138.

10 Holick MF. Vitamin D and bone health. Journal of Nutrition 1996126 (4 Suppl) 1159S-1164S.

11 Locatelli V \& Bianchi VE. Effect of GH/IGF-1 on bone metabolism and osteoporsosis. International Journal of Endocrinology 20142014235060. (doi:10.1155/2014/235060)

12 Qin LQ, He K \& Xu JY. Milk consumption and circulating insulin-like growth factor-I level: a systematic literature review. International Journal of Food Sciences and Nutrition 200960 (Suppl 7) 330-340. (doi:10.1080/09637480903150114)

13 Holmes MD, Pollak MN, Willett WC \& Hankinson SE. Dietary correlates of plasma insulin-like growth factor I and insulin-like growth factor binding protein 3 concentrations. Cancer Epidemiology, Biomarkers \& Prevention 200211 852-861.

14 Stern N, Lee DB, Silis V, Beck FW, Deftos L, Manolagas SC et al. Effects of high calcium intake on blood pressure and calcium metabolism in young SHR. Hypertension 19846 639-646. (doi:10.1161/ 01.HYP.6.5.639)

15 National Center for Health Statistics. Plan and operation of the Third National Health and Nutrition Examination Survey, 1988-1994. Series 1: programs and collection procedures. Vital Health Stat 1. 1-407, 1994.

16 NHANES CNCfHS. NHANES: 1999-2000 - lab methods 2010 (cited 2nd September 2014). Available from: http://www.cdc.gov/nchs/nhanes/ nhanes1999-2000/lab_methods_99_00.htm.

17 Sabanayagam C \& Shankar A. Serum calcium levels and hypertension among U.S. adults. Journal of Clinical Hypertension 201113 716-721. (doi:10.1111/j.1751-7176.2011.00503.x)

18 Shiels MS, Rohrmann S, Menke A, Selvin E, Crespo CJ, Rifai N, Dobs A, Feinleib M, Guallar E \& Platz EA. Association of cigarette smoking, alcohol consumption, and physical activity with sex steroid hormone levels in US men. Cancer Causes \& Control 200920 877-886. (doi:10. 1007/s10552-009-9318-y)

19 Looker AC, Orwoll ES, Johnston CC Jr, Lindsay RL, Wahner HW, Dunn WL et al. Prevalence of low femoral bone density in older U.S. adults from NHANES III. Journal of Bone and Mineral Research 199712 1761-1768. (doi:10.1359/jbmr.1997.12.11.1761)

20 Berrigan D, Potischman N, Dodd KW, Nicar M, McQuillan G, Lavigne JA et al. Serum levels of insulin-like growth factor-I and insulinlike growth factor-I binding protein-3: quality control for studies of stored serum. Cancer Epidemiology, Biomarkers \& Prevention 200716 1017-1022. (doi:10.1158/1055-9965.EPI-07-0044)

21 Papatheodorou SI, Rohrmann S, Lopez DS, Bradwin G, Joshu CE, Kanarek $\mathrm{N}$ et al. Association between endogenous sex steroid hormones and insulin-like growth factor proteins in US men. Cancer Causes \& Control 201425 353-363. (doi:10.1007/s10552-013-0336-4)

22 Maruyama K, Iso H, Ito Y, Watanabe Y, Inaba Y, Tajima K et al. Associations of food and nutrient intakes with serum IGF-I, IGF-II, IGFBP-3, TGF-b1, total SOD activity and sFas levels among middle-aged Japanese: the Japan Collaborative Cohort study. Asian Pacific Journal of Cancer Prevention 200910 (Suppl) 7-22. (doi:10.1158/1940-6207.CAPR11-0407)

23 Bringhurst F, Demay M, Krane S \& Kronenberg H. Bone and mineral metabolism in health and disease. In Harrion's Prinicples of Internal Medicine. Eds A Fauci, D Longo, D Kasper, E Braunwald, J Jameson, J Loscalzo et al. New York: McGraw-Hill; 2008.

24 Sheng MH, Zhou XD, Bonewald LF, Baylink DJ \& Lau KH. Disruption of the insulin-like growth factor-1 gene in osteocytes impairs developmental bone growth in mice. Bone 201352 133-144. (doi:10.1016/ j.bone.2012.09.027)

25 Sheng MH, Lau KH \& Baylink DJ. Role of osteocyte-derived insulin-like growth factor I in developmental growth, modeling, remodeling, and regeneration of the bone. Journal of Bone Metabolism 201421 41-54. (doi:10.11005/jbm.2014.21.1.41)

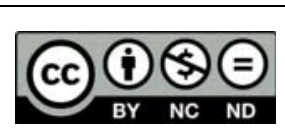

This work is licensed under a Creative Commons Attribution-NonCommercial-NoDerivs 4.0 International License. 
26 Wong CK, Lai T, Holly JM, Wheeler MH, Stewart CE \& Farndon JR. Insulin-like growth factors (IGF) I and II utilize different calcium signaling pathways in a primary human parathyroid cell culture model. World Journal of Surgery 200630 333-345. (doi:10.1007/s00268-0050339-8)

27 Bonjour JP, Chevalley T, Ferrari S \& Rizzoli R. The importance and relevance of peak bone mass in the prevalence of osteoporosis. Salud Pública de México 200951 (Suppl 1) S5-S17. (doi:10.1590/S0036$36342009000700004)$

28 Young NJ, Metcalfe C, Gunnell D, Rowlands MA, Lane JA, Gilbert R et al. A cross-sectional analysis of the association between diet and insulin-like growth factor (IGF)-I, IGF-II, IGF-binding protein (IGFBP)2, and IGFBP-3 in men in the United Kingdom. Cancer Causes \& Control 201223 907-917. (doi:10.1007/s10552-012-9961-6)

29 Ma J, Giovannucci E, Pollak M, Chan JM, Gaziano JM, Willett W et al. Milk intake, circulating levels of insulin-like growth factor-I, and risk of colorectal cancer in men. Journal of the National Cancer Institute 200193 1330-1336. (doi:10.1093/jnci/93.17.1330)

30 Dickinson A, Blatman J, El-Dash N \& Franco JC. Consumer usage and reasons for using dietary supplements: report of a series of surveys. Journal of the American College of Nutrition 201433 176-182. (doi:10.1080/07315724.2013.875423)

31 Norat T, Dossus L, Rinaldi S, Overvad K, Gronbaek H, Tjonneland A et al. Diet, serum insulin-like growth factor-I and IGF-binding protein-3 in European women. European Journal of Clinical Nutrition 200761 91-98. (doi:10.1038/sj.ejcn.1602494)

32 Adami S, Zivelonghi A, Braga V, Fracassi E, Gatti D, Rossini M et al. Insulin-like growth factor-1 is associated with bone formation markers, PTH and bone mineral density in healthy premenopausal women. Bone 201046 244-247. (doi:10.1016/j.bone.2009.10.011)

33 Siegel R, Ma J, Zou Z \& Jemal A. Cancer statistics. CA: A Cancer Journal for Clinicians 201464 9-29. (doi:10.3322/caac.21208)
34 McGreevy KM, Hoel BD, Lipsitz SR \& Hoel DG. Impact of nutrients on insulin-like growth factor-I, insulin-like growth factor binding protein-3 and their ratio in African American and white males. Public Health Nutrition 200710 97-105. (doi:10.1017/ S1368980007217999)

35 Viesti ACR, Salgado W Jr, Pretti da Cunha Tirapelli D \& dos Santos JS. The expression of LEP, LEPR, IGF1 and IL10 in obesity and the relationship with microRNAs. PLoS ONE 20149 e93512. (doi:10.1371/ journal.pone.0093512)

36 Mason C, Xiao L, Duggan C, Imayama I, Foster-Schubert KE, Kong A et al. Effects of dietary weight loss and exercise on insulin-like growth factor-I and insulin-like growth factor-binding protein-3 in postmenopausal women: a randomized controlled trial. Cancer Epidemiology, Biomarkers \& Prevention 201322 1457-1463. (doi:10.1158/1055-9965. EPI-13-0337)

37 Ohlsson C, Mellstrom D, Carlzon D, Orwoll E, Ljunggren O, Karlsson MK et al. Older men with low serum IGF-1 have an increased risk of incident fractures: the MrOS Sweden study. Journal of Bone and Mineral Research 201126 865-872. (doi:10.1002/jbmr.281)

38 Seck T, Scheidt-Nave C, Leidig-Bruckner G, Ziegler R \& Pfeilschifter J. Low serum concentrations of insulin-like growth factor I are associated with femoral bone loss in a population-based sample of postmenopausal women. Clinical Endocrinology 200155 101-106. (doi:10.1046/ j.1365-2265.2001.01278.x)

39 Lumachi F, Camozzi V, Doretto P, Tozzoli R \& Basso SM. Circulating PTH, vitamin D and IGF-I levels in relation to bone mineral density in elderly women. In Vivo 201327 415-418.

40 Gillberg P, Olofsson H, Mallmin H, Blum WF, Ljunghall S \& Nilsson AG. Bone mineral density in femoral neck is positively correlated to circulating insulin-like growth factor (IGF)-I and IGF-binding protein (IGFBP)-3 in Swedish men. Calcified Tissue International 200270 22-29. (doi:10.1007/s002230020048)

Received in final form 10 July 2015

Accepted 3 August 2015 http://www.endocrineconnections.org DOI: 10.1530/EC-15-0039
(C) 2015 The authors Published by Bioscientifica Ltd
This work is licensed under a Creative Commons Attribution-NonCommercial-NoDerivs 4.0 International License. 